\title{
Hydraulic studies of the throughput of the water intake structure of the Tuyamuyun hydroelectric complex
}

\author{
Ulmas Khusankhodjaev ${ }^{1 *}$, and Odil Kadyrov ${ }^{2}$ \\ ${ }^{1}$ Tashkent architectural and construction institute, Tashkent, Uzbekistan \\ ${ }^{2}$ Tashkent Institute of Irrigation and Agricultural Mechanization Engineers, Tashkent, Uzbekistan
}

\begin{abstract}
The article presents the results of experimental studies to determine the throughput of the right-bank water intake structure and bottom galleries, the hydraulic regime in the galleries, and the movement of bottom sediments in them. Based on the results of the studies, a series of curves were obtained for the dependence of the discharge on the water horizon in the upper pool and the value of the opening of the gate of the intake structure. Checking the work of the galleries together with the working water intake holes showed that there is no mutual influence of them on each other. The total consumption of water passed through the water intake and galleries is practically equal to the sum of the consumption of water passed through these structures separately. It was found that the main amount of sediment accumulated in the headwater will fall into the left gallery, while slightly less (about one third) will fall into the right span, and only a small remainder leaves through the weir, while the water flow rate was distributed as follows: $Q_{\text {gal }}=1.65 Q_{\text {water }}$.
\end{abstract}

\section{Introduction}

Currently, large-scale measures are being taken in the Republic of Uzbekistan to improve the design of hydraulic structures, ensure their reliable and safe operation, improve the throughput and operating mode of spillway structures, and improve their effective mechanisms of work. The Strategy of Actions for the Further Development of the Republic of Uzbekistan for 2017-2021 outlines tasks, including "development of land reclamation and irrigation facilities to increase the competitiveness of the national economy." The solution of these tasks, during a period of shortage, including one important task is to conduct research work aimed at developing rational design methods and efficient operation, based on account of water resources of emerging damages, failures, and accidents, as well as stress-strain processes in the work of hydraulic structures of ground irrigation systems. In this regard, we carried out hydraulic studies of the throughput capacity of the water intake structure of the Tuyamuyun hydroelectric complex [1-14]. The Tuyamuyun hydroelectric complex on the Amu Darya River consists of a blind earthen dam, a spillway dam, a hydroelectric power station building, left-bank and right-bank water intakes with

\footnotetext{
*Corresponding author: husan_1954@mail.ru
} 
bottom galleries [15-24]. The spillway dam has 10 spans, 9 of which are of the same type in the form of bottom holes with dimensions of $12 \times 6 \mathrm{~m}$, and the extreme right-bank span is made as a surface spillway of a practical profile. The regulation of flow rates in all outlets of the hydroelectric complex is carried out by segment gates. The water part has a slope of 1: 20 and ends with a tooth. A split wall is installed between the spillway dam and the HPP building in downstream. The bottom galleries of the building of the hydroelectric power station and two water intakes go directly to the downstream of the dam [25-33]. The maximum discharge passed by the dam is $13000 \mathrm{~m} 3 / \mathrm{s}$ at a water level in the upper pool of $130.0 \mathrm{~m}$ and $7300 \mathrm{~m} 3 / \mathrm{s}$ at a level of $120.0 \mathrm{~m}$. Water flow rates passing through the left-bank and right-bank water intakes are respectively equal to $500 \mathrm{~m} 3 / \mathrm{s}$ and $120 \mathrm{~m} 3 / \mathrm{s}$.

In the downstream, two levels of water horizons are possible - maximum $116.6 \mathrm{~m}$, minimum $112.4 \mathrm{~m}$, and taking into account the total erosion $104.75 \mathrm{~m}$. Water intake facilities are designed to supply water to canals for irrigation needs. The investigated water intake unit is a two-span head structure with a baffle wall. The holes have a cross-section of $5 \times 4 \mathrm{~m}$ each. Water flow rates are regulated by segment gates. Directly behind the gates, there is a stilling well, $2 \mathrm{~m}$ deep, $3 \mathrm{~m}$ long, $5 \mathrm{~m}$ wide in each span. Behind the well, after a straight insert $8 \mathrm{~m}$ long, a turn of 500 begins, then a rectangular outlet channel $213 \mathrm{~m}$ long. The outlet channel behind the segmental gates at a length of $163 \mathrm{~m}$ is divided by a bull; then the channel goes in one section with a width of $b=12 \mathrm{~m}$. Directly under the water intake structure threshold, there are two bottom galleries of a closed rectangular section measuring $5 \times 2.5 \mathrm{~m}$ with a threshold level of $110.0 \mathrm{~m}$; the bottom level of the galleries at the exit is $105.0 \mathrm{~m}$. At the end of the galleries, there are cameras with two rows of flat shutters. Sediments are discharged directly into the downstream of the dam.

\section{Materials and Methods}

The main research questions were:

1. Determination of the throughput of water intake and bottom galleries.

2. Determination of the optimal relationship between water intake and bottom galleries.

3. Investigation of the hydraulic regime of the movement of bottom sediments in the galleries.

The experiments were carried out on a spatial eroded model at a scale

1: 40 life-size.

The section of the river was reproduced. The Amu Darya in the alignment of the hydroelectric complex is $400 \mathrm{~m}$ long, of which $80 \mathrm{~m}$ above the alignment and $320 \mathrm{~m}$ below. According to the method based on the principle of gravitational similarity (according to Froude), modeling was carried out on a scale of 1:80.

The capacity of the intake structure was determined with both open and closed bottom galleries. At the same time, a constant water horizon in the headwater was maintained on the model. 119.0; 122.0; 124.0; etc. Only the opening value of the segmented gates and the costs changed.

\section{Results and Discussion}

Below are the results of experimental studies.

a) By the intake structure

Based on the experiments, a series of curves were obtained to depend on the discharge on the water horizon in the headwater and the value of the gate opening. 


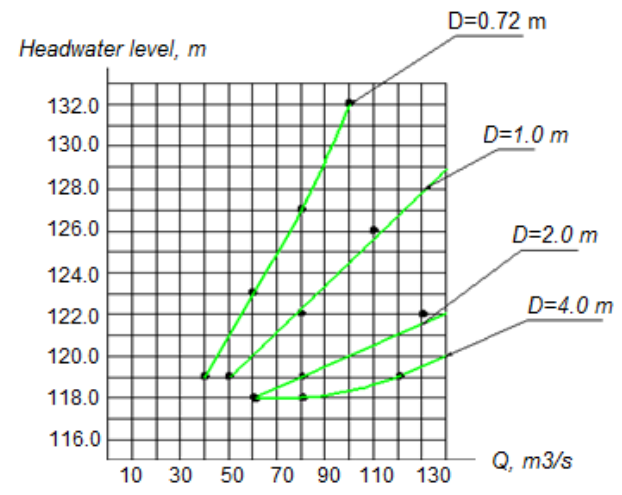

Fig 1. Curves of water flow rate depend on the water horizon in the headwater and the gate's opening Figure 2 shows the curves of the water intake capacity combined with the calculated ones.

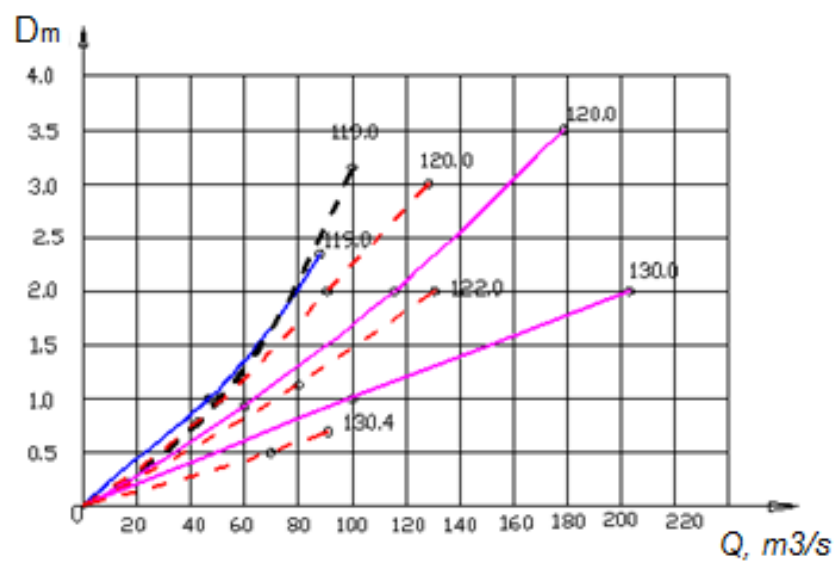

Fig. 2 Curves of water intake capacity combined with calculated ones.

Their difference from each other is explained by the overestimation of the discharge coefficient in the formulas and the failure to consider the spatial conditions of the approach of the flow to the structure. The data on the throughput was the basis for calculating the coefficient of water intake, which was determined by the formula:

$$
\mu=\frac{Q}{\omega \sqrt{2 g(\mathrm{H}-h)}}
$$

The experiments were carried out with constant water levels in the headwater (130.0 and $120.0 \mathrm{~m}$ ) and various gate openings. It was found that the value of $\mu$ depends on the opening of gates and water horizons in the headwater. 


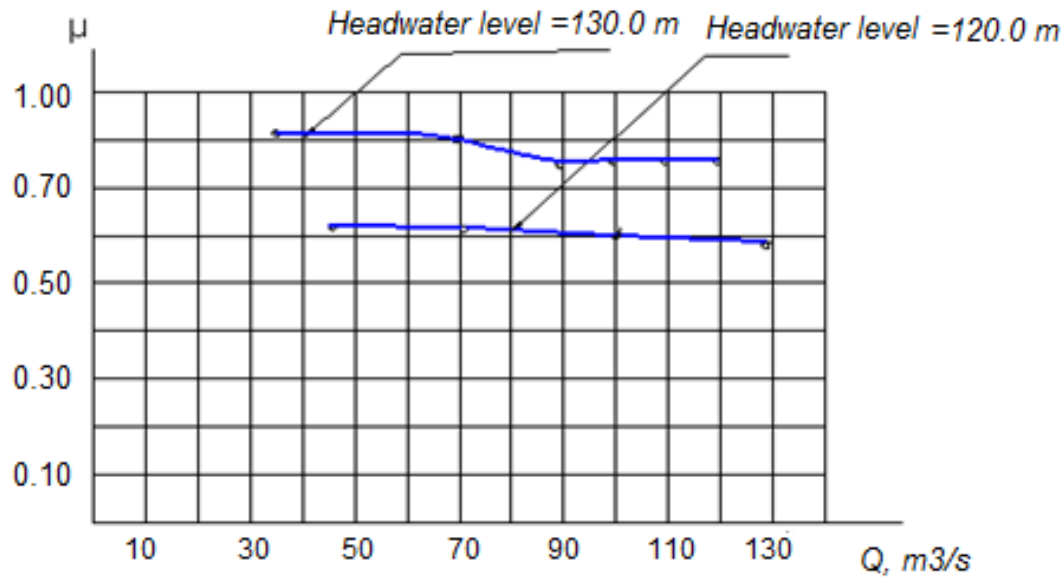

Fig. 3 Curves of dependence of coefficient $\mu$ on water consumption at different water levels in the upper pool

b) Along the bottom galleries.

The throughput of the bottom galleries was determined both without taking into account the effect of the operation of the openings of the intake structure and the spillway dam and during the operation of the latter,

At the same time, the water horizon in the downstream of the dam was set in two positions 115.70 - living conditions and at the level of $106.0 \mathrm{~m}$, taking into account the general erosion of the channel.

In the experiments, the water horizons in the headwater were set constant from 110.0 to 130.0 with an interval of $2.0 \mathrm{~m}$, and the water discharge also varied accordingly.

Based on these experiments, the curves of the dependence of the water discharge on the water horizon of the upper pool were constructed.

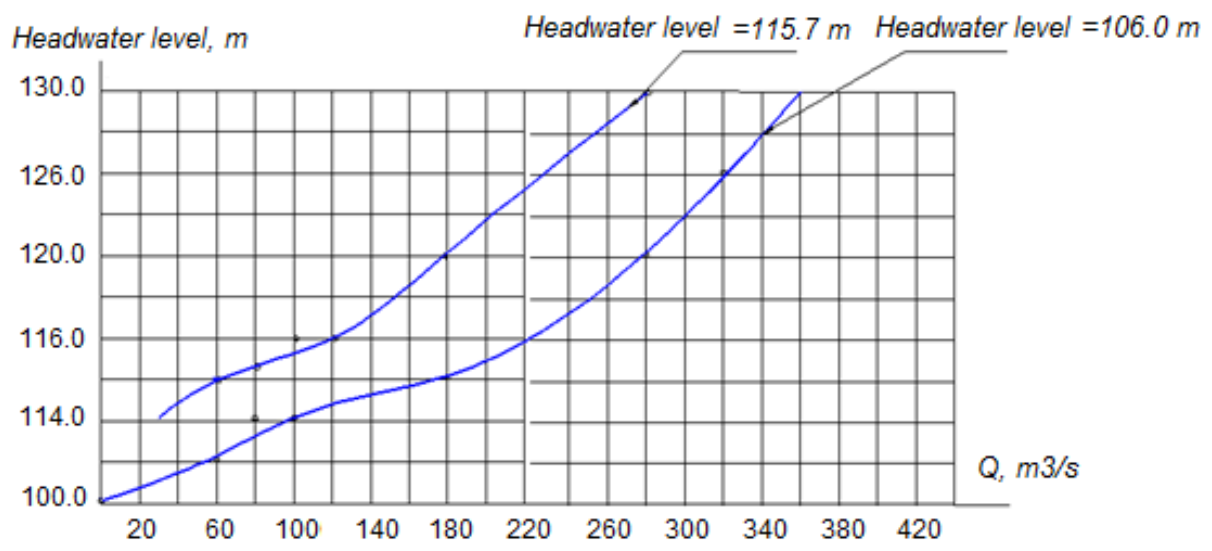

Fig. 4. Curves of dependence of water discharge on the horizon waters of the upstream and downstream of the bottom galleries.

Experiments have also established that at the maximum elevation of the headwater - 130.0 $\mathrm{m}$ and completely open holes through the bottom galleries, a water flow rate equal to $\mathrm{Q}=$ $272 \mathrm{~m} 3 / \mathrm{s}$ passes, with a water horizon in the lower pool of 115.7, and Qgil $=345 \mathrm{~m} 3 / \mathrm{s}$ with the water level in the downstream pool $106.0 \mathrm{~m}$ 
Checking the work of the galleries together with the working water intake holes showed that there is no mutual influence of them on each other. The total discharge passed through the water intake, and the galleries are practically equal to the sum of the water discharges passed through these structures separately. In the experiment, observations were made of the operation mode of the bottom galleries at different discharge rates and water horizons in the downstream.

So, when passing low flow rates (up to $Q=60 \mathrm{~m} 3 / \mathrm{s}$ ), the galleries operate with an incomplete cross-section, with a decline in the curve of the free surface at the entrance and a rapid flow out of the galleries. At flow rates $\mathrm{Q}=80-100 \mathrm{~m} 3 / \mathrm{s}$, the flow periodically overflows the entrance, and at $\mathrm{Q}=120 \mathrm{~m} 3 / \mathrm{s}$, the entrance to the galleries is flooded by 1.0 $\mathrm{m}$. With a water level in the downstream of 106.0, the exit galleries do not work with a full section.

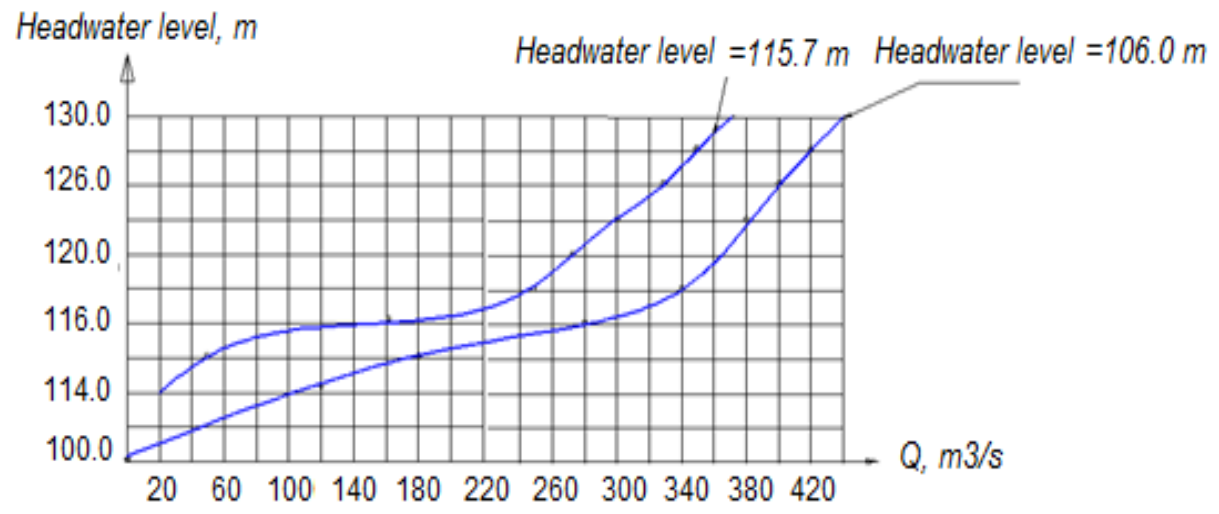

Fig. 5. Curves of water discharge dependence on the water horizon of the upper and downstream ponds with joint work of bottom galleries and water intake.

In the experiment, observations were made of the operating mode of the bottom galleries at different flow rates and water levels in the downstream.

So, when passing low flow rates (up to $\mathrm{Q}=60 \mathrm{~m} 3 / \mathrm{s}$ ), the galleries operate with an incomplete cross-section, with a decline in the curve of the free surface at the entrance and a rapid exit of the flow from the galleries. At flow rates $Q=80-100 \mathrm{~m} 3 / \mathrm{s}$, the flow periodically overflows the entrance, and at $\mathrm{Q}=120 \mathrm{~m} 3 / \mathrm{s}$, the entrance to the galleries is flooded by $1.0 \mathrm{~m}$. With a water level in the downstream of 106.0, the exit galleries do not work with a full section.

When the water horizon in the downstream reaches 115.7, the exit from the galleries is completely flooded, and they act as pressure pipes.

c) According to the regime of movement of bottom sediments

Experiments established that the main amount of sediment accumulated in the headwater would fall into the left gallery, while a little less (about one third) will fall into the right span, and only a small remainder leaves through the weir hole. In this case, the water consumption was distributed as follows: Qgal $=1.65$ Qwater With an increase in the number of working openings of the weir dam, the proportion of sediment abstracted by them slightly increased, but as before, the bulk of the sediment rushes into the galleries. 


\section{Conclusions}

Based on the research, the following conclusions can be drawn:

- when determining the throughput of the water intake, the value of the discharge coefficient in formula (1) should be taken according to the experimental data shown in Figure.

- checking the operation of the galleries together with the working water intake holes showed that there is no mutual influence of them on each other. The total consumption of oxen passed through the water intake and galleries are equal to the sum of the water consumption passed through these structures separately.

- recommended ratio between water intake and gallery water flow rates

- $\quad$ is $\mathrm{Q}_{\mathrm{gal}}=1.6$ Qin. which will allow almost all bottom sediments to be dumped into the downstream.

\section{References}

1. Kaveshnikov A T Nguyen V D Local erosion behind culverts equipped with two cone gates Building Section Moscow, (2002)

2. Kiselev P G Handbook of hydraulic calculations Publishing House Ecolit Moscow, (2011)

3. Levy 11 Modeling hydraulic phenomena Publishing House "Energy" Moscow, (1967)

4. Nesterov M V Waterworks M INFRAM Uzbekistan Tashkent, (2018)

5. Khusanhodjayev U Baimatov Sh Results of studies to determine the depth of local erosion in the lower basin of the Tuyamuyunsky hydroelectric complex Architecture construction design No Uzbekistan Tashkent, (2014)

6. Маджидов.И.,У.ФайзиевХ.,ХусанходжаевУ.И.,Рахматов.Н

Гидротехника иншоотлари. p.327, Тошкент (2019)

7. Vizgo M S Operational measures and ways to reduce local erosion behind hydraulic structures Ed. Science Uzbekistan Tashkent, (1996)

8. Bradlow D Palmiery A Salman Regnlatory Framework for Dam Safaly Uzbekistan Tashkent, (2003)

9. RozanovNP Waterworks M Moscow, (1985)

10. Wexler A B Reliability social and environmental facilities: risk assessment and decision making M Sankt - Peterburg, (2002)

11. Mirtskhulaeva S E Reliability of irrigation and drainage facilities Asr Uzbekistan Tashkent, (1974)

12. Altunin V S Ameliorative channels in earth bed Moskow Publishing House Kolos, (1979)

13. Altunin S T Water intake units and reservoir Moskow Publishing House Kolos, (1964)

14. Artamonov K F Adjusting constructions for water intake on river in piedmont districts Frunze Edition of Academy of Sciences Kyrgyzstan, (1965)

15. Astafev V A Barkov N K Hydroturbines and their operation Moskow and Leningrad Publishing House'«Energy», (1965)

16. Achkasov G P Ivanov E S Technology and organization of repair of meliorative hyrotechnical constructions Moskow Publishing House Kolos, (1984)

17. Bakiyev M Nosirov B Khajakulov R Hydraulic structures Textbook Tashkent "Vilim" publishing house, (2004)

18. Bakiev M R Tursunov T N Ikramov N M About negative hydraulic processes in big pumping stations Collec. Of scientific articles SPb SPbGPU, (2006)

19. NR 23.13330. Foundations of hydraulic structures. (2011)

20. Stories of L.N. and other hydraulic structures. T. I, II. PH .: Stroyizdat, - p.880, (2010) 
21. Slissky.S.M. Hydraulic calculations of high-pressure hydraulic structures. Ed. Energy PH (1979)

22. B.E. Vedeneeva. Guide to field studies of the resistance of rocky foundations of hydraulic structures to shear. P01-73. Ministry of Energy of the USSR, L., VNIIG., 1973 [23]Recommendations on the methodology for determining the modulus of deformation of rocky soils in the massif using stamps. P-877-89. Ministry of Energy of the USSR, M., Hydroproject, (1989)

23. Krutov A., Choriev R., Norkulov B., Mavlyanova D. and Shomurodov A. Mathematical modelling of bottom deformations in the kinematic wave approximation. IOP Conf. Ser. Mater. Sci. Eng. 1030, 012147 (2021).

24. Bazarov D., Vatin N., Obidov B., and Vokhidov O. Hydrodynamic effects of the flow on the slab of the stand in the presence of cavitation. IOP Conf. Ser. Mater. Sci. Eng. 1030, 012110 (2021).

25. Bazarov D., Markova I., Raimova I., Sultanov Sh. Water flow motion in the vehicle of main channels. IOP Conf. Ser. Mater. Sci. Eng. 883, 012025 (2020).

26. Bazarov D., Markova I., Sultanov S. and Kattakulov F. Dynamics of the hydraulic and alluvial regime of the lower reaches of the Amudarya after the commissioning of the Takhiatash and Tuyamuyun hydrosystems. IOP Conf. Ser. Mater. Sci. Eng. 1030, 012110 (2021).

27. Krutov A., Norkulov B., Uljaev F., and Jamalov F. Results of a numerical study of currents in the vicinity of a damless water intake. IOP Conf. Ser. Mater. Sci. Eng. 1030, 012121 (2021).

28. Krutov A., Norkulov B., Artikbekova F., Nurmatov P. Optimal location of an intake at a reservoir prone to salt diffusion. IOP Conf. Ser. Mater. Sci. Eng. 869(7), 072020, (2020)

29. Uralov B., Rakhmatov N., Khidirov S., Uljaev F., Raimova I. Hydraulic modes of damless water intake. IOP Conf. Ser. Mater. Sci. Eng. 1030(1), 012123 (2021)

30. Bazarov D. and Vokhidov O. Extinguishing Excess Flow Energy in Spillway Structures. In book: Proceedings of EECE 2020, LNCE 150, pp. 535-545, (2021) DOI: 10.1007/978-3-030-72404-7_52

31. Matyakubov B., Begmatov I., Raimova I. and Teplova G. Factors for the efficient use of water distribution facilities. IOP Conf. Ser. Mater. Sci. Eng. 883, 012025 (2020).

32. Obidov B., Vokhidov O., Tadjieva D., Kurbanova, U., Isakov A. Hydrodynamic effects on the flow elements of the downstream devices in the presence of cavitation. IOP Conf. Ser. Mater. Sci. Eng. 1030, 012114 (2021).

33. Bazarov D., Norkulov B., Vokhidov O., Uljaev F., Ishankulov, Z. Two-dimensional flow movement in the area of protective regulatory structures. IOP Conf. Ser. Mater. Sci. Eng. 890, 012162 (2020) 